\title{
FLAME-SPRAY PYROLYSIS PREPARATION OF PEROVSKITES FOR METHANE CATALYTIC COMBUSTION
}

\author{
Gian Luca Chiarello, llenia Rossetti and Lucio Forni* \\ Dip. di Chimica Fisica ed Elettrochimica, Università degli Studi di Milano \\ v. C. Golgi, 19 I-20133 Milano, Italy
}

\begin{abstract}
A flame spray pyrolysis apparatus was set-up and optimised for the preparation of perovskitic mixed metal oxides in nanoparticle-size powder form. $\mathrm{LaCoO}_{3}$ was chosen as test catalyst, aiming at correlating crystallinity, surface area, particle size, catalytic activity and durability with some fundamental operating parameters of the apparatus. In particular, feeding rate of precursors solution, flow rate of the $\mathrm{O}_{2} / \mathrm{CH}_{4}$ mixture for the igniter and flow rate and linear velocity of the main dispersing-oxidising oxygen have been thoroughly analysed. The activity of the prepared samples was tested for the catalytic flameless combustion of methane, a reaction requiring a proper combination of activity and thermal stability of the catalyst. Provided a crystalline perovskitic phase forms, activity increases with increasing surface area of the powder. By contrast, the higher the initial sintering of catalyst particles within the flame, the higher is thermal stability. Tuning up of operating parameters allows to properly address the desired catalyst properties.
\end{abstract}

Keywords: Flame-spray-pyrolysis; Catalytic flameless combustion of methane; $\mathrm{LaCoO}_{3}$ perovskite.

*Corresponding author: Fax: +39-02-50314300; e-mail: lucio.forni@unimi.it 


\section{1 - INTRODUCTION}

Perovskitic mixed oxides are interesting materials for a wide variety of applications, including anodes for solid oxides fuel cells, gas sensors and, mostly, catalysts for partial or full oxidation reactions. Among these, the catalytic flameless combustion (CFC) of hydrocarbons, particularly of methane, is of ever growing importance for energy production. Indeed, $\mathrm{CFC}$ can be carried out at lower temperature $\left(<800^{\circ} \mathrm{C}\right)$ with respect to usual combustion, so virtually suppressing any $\mathrm{NO}_{x}$ formation. Moreover, the catalyst strongly enhances selectivity towards full oxidation, so eliminating other noxious pollutants, such as $\mathrm{CO}$ and partial oxidation products.

The main catalyst requirements for CFC of methane are phase purity, ionic mobility through the crystal lattice, high surface area and good resistance to high temperature, uneasily obtainable all at once. A pure perovskitic phase forms at high temperature, usually $>700^{\circ} \mathrm{C}$. Hence, traditional preparation methods were based on repeated cycles of calcination-milling of the precursors single oxides, leading to well crystallised and thermally resistant materials, but with very low surface area. For this reason this procedure is still used for preparing ceramic materials only. In order to increase surface area for catalytic use, many different sol-gel preparation routes were developed [1-8] leading to a pure perovskitic phase at lower temperature. Unfortunately, the lower the preparation temperature, the lower is thermal resistance of the material. Hence, for high temperature catalytic application, these routes reveal unsuitable, due to easy particle sintering during use. Recently, high energy mechanical milling was also proposed to obtain mixed oxides through low temperature solid state reaction [9-11]. However, application to $\mathrm{LaCoO}_{3}$ and $\mathrm{LaMnO}_{3}$ did not lead to complete precursors conversion even in the presence of milling aids and for prolonged reaction time [12]. 
Several years ago we developed a flame hydrolysis $(\mathrm{FH})$ technique, so to combine high surface area, and hence high catalytic activity, with good thermal stability under the high temperature CFC working conditions $[7,8,13]$. The FH-prepared perovskitic catalysts possessed a high phase purity and nanometer size particles, relatively high surface area (up to ca. $20 \mathrm{~m}^{2} / \mathrm{g}$ ) and exceptionally high thermal stability [7,8,13-16]. The method was based on nebulising an aqueous solution of the oxide precursors in a $\mathrm{H}_{2}+\mathrm{O}_{2}$ flame. The residence time of the droplets within the flame was a few milliseconds, preventing any extensive sintering of the powder obtained. Catalytic activity and mostly thermal stability were satisfactory, together with high crystallinity and purity, since no trace of precursors, nor of carbonaceous residua were ever noticed in the produced catalysts. However, the productivity was very low, just a few $\mathrm{mg} / \mathrm{h}$, and rather energy expensive.

Many research groups developed different flame-based techniques for the synthesis of oxides and some of them are presently adopted for commercial production of $\mathrm{SiO}_{2}$ or $\mathrm{TiO}_{2}$ nanoparticles [17-19]. Formerly, the main limitation was due to the availability of volatile precursors to be fed to the flame. More recently, aerosol or liquid-feed flame pyrolysis (FP) allowed to overcome the low productivity problem, hence widely extending the application field of flame synthesis [20-39]. Among the methods proposed, the spray FP seems the most interesting for the production of perovskitic oxides, since it does not require volatile precursors. It is based on a specially designed burner [20-31,39], fed with oxygen through a nozzle, where an organic solution of the precursors is also fed, the solvent acting as the fuel for the flame. The mixture is ignited by a surrounding ring of $\mathrm{O}_{2} / \mathrm{CH}_{4}$ flamelets. High productivity and phase purity are reported, together with nanometer particle size and hence exceptionally high surface area $\left(>100 \mathrm{~m}^{2} / \mathrm{g}\right)$. The relatively high temperature of the flame in principle should ensure also thermal stability, once the main operating parameters have been optimised. 
The aim of the present work was to set-up and optimise a FP apparatus for preparing perovskitic catalysts for the CFC of methane. Attention was paid to the structural homogeneity of the product, trying to extend the preparation procedure, mainly reported for single oxides synthesis, to mixed oxides. $\mathrm{LaCoO}_{3}$ was chosen as model catalyst for system optimisation, investigating the effect of some significant nozzle operating parameters on surface area, particle size, phase purity, crystal structure, catalytic activity for the test reaction and thermal resistance of the catalyst. In the present paper we report in detail the effect of liquid feeding rate, of $\mathrm{O}_{2} / \mathrm{CH}_{4}$ mixture flow rate and of flow rate and linear velocity of the dispersing-oxidising oxygen.

\section{2 - EXPERIMENTAL}

\section{1 - Precursors solution}

$\mathrm{La}\left(\mathrm{CH}_{3} \mathrm{COO}\right)_{3} \cdot 2 \mathrm{H}_{2} \mathrm{O}$ (Aldrich, purity > 99.9\%) and $\mathrm{Co}\left(\mathrm{CH}_{3} \mathrm{COO}\right)_{2} \cdot 4 \mathrm{H}_{2} \mathrm{O}$ (Merck, purum), in the desired ratio and metal concentration, were dissolved in propionic acid under vigorous stirring at $60^{\circ} \mathrm{C}$.

\section{2 - Flame-pyrolysis (FP) apparatus}

Our home-made FP apparatus is composed of three sections: a) the flame reactor (burner), b) the feeding rate control devices for gaseous and liquid reagents and $c$ ) the catalyst powder collection system. A schematic representation of the system is given in Fig. 1.

The burner consists of a capillary tube (inner diameter $0.6 \mathrm{~mm}$ ) ending in the centre of a vertical nozzle and connected with a syringe pump (Harvard, mod. 975), feeding the solution of the mixed oxide precursors. The nozzle is fed with oxygen (SIAD, purity 
99.95\%), acting both as oxidant and as dispersing agent, so to form very small droplets of solution. The main flame is ignited and supported by a ring of twelve premixed $\mathrm{O}_{2}+\mathrm{CH}_{4}$ (SIAD, purity 99.0\%) flamelets. Gas flow rate was controlled by means of MKS Instruments (mod. 1259C) mass flow regulators, governed by a MKS Instruments (mod. 247 C) control unit. Oxygen linear velocity and pressure drop across the nozzle were varied by selecting a proper feeding rate and/or by adjusting the nozzle discharge cross section and geometry. Calibrated manometers allowed to control the oxygen inlet pressure. A further ring of small air feeding nozzles (not shown in Fig.1) allowed to keep an oxidising atmosphere around the burner and helped in conveying the product to the powder collection section. The latter consists of a cylindric electrostatic precipitator, based on a multipin effluviator, surrounded by a coaxial collector, maintained at a $10 \mathrm{kV}$ potential difference [7]. The system allowed to recover ca. $80 \%$ of the produced powder.

\section{3 - Catalyst characterisation}

Specific surface area (SSA) was measured by $\mathrm{N}_{2}$ adsorption/desorption at $77 \mathrm{~K}$ by a Micromeritics ASAP 2010 apparatus, after outgassing at $300^{\circ} \mathrm{C}$ for at least $6 \mathrm{~h}$. All the recorded isotherms were of type III, indicating a non-porous dense material. This permits a direct correlation between SSA and average particle size of the powder. Scanning electron microscopy (SEM) analysis was carried out on a LEICA LEO 1430 instrument. A Phillips PW1820 powder diffractometer, with Ni-filtered Cu k $\alpha$ radiation $(\lambda=1.5148 \AA)$, was employed for structural analysis. The diffractograms obtained were compared with literature data [40] for phase recognition. If not specifically indicated in text, no different phases besides perovskite-like $\mathrm{LaCoO}_{3}$ were observed.

\section{4 - Catalytic activity}


The catalytic activity tests for the CFC of methane were carried out by means of a bench-scale continuous reaction unit. A quartz tubular reactor (i.d. $=7 \mathrm{~mm}$ ) was heated by a tubular furnace through two heavy hemicylindrical metal blocks. The catalyst (ca. $0.2 \mathrm{~g}$, 0.15-0.25 mm particle size, diluted 1:6.5 by weight with quartz powder of the same particle size) was placed in the isothermal middle part of the reactor, between two flocks of quartz wool. The void part of the reactor tube, above and below the catalyst bed, was filled with quartz beads (10-20 mesh). Prior to each run, the catalyst was activated in flowing air (20 $\mathrm{cm}^{3} / \mathrm{min}$ ), while increasing temperature by $10^{\circ} \mathrm{C} / \mathrm{min}$ up to $600^{\circ} \mathrm{C}$, then kept for $1 \mathrm{~h}$. The activity tests were carried out by feeding a mixture composed of 0.5 vol\% $\mathrm{CH}_{4}, 49.5$ vol\% He and 50 vol\% air, while increasing temperature by $2^{\circ} \mathrm{C} / \mathrm{min}$ from 250 up to $600^{\circ} \mathrm{C}$. The outlet gas was analysed in line by means of an HP 5890 gas chromatograph, equipped with Porapak Q and MS-5 columns. The total flow rate of the gas mixture was calculated by referring to the mass of active phase, so to have for every test an identical value of the time factor $\tau=\mathrm{W} / \mathrm{F}=2.5$ ( $\mathrm{mg}$ of perovskite $\cdot \mathrm{min} / \mathrm{cm}^{3}$ of overall gas flow rate).

\section{5 - Accelerated thermal deactivation tests}

Accelerated thermal deactivation tests were conducted after keeping the sample at the temperature $\left(T_{f}\right)$ of maximum conversion for $48 \mathrm{~h}$, while measuring the residual conversion every $24 \mathrm{~h}$. Then cycles of reaction/deactivation were accomplished, by increasing temperature $\left(10^{\circ} \mathrm{C} / \mathrm{min}\right)$ up to $800^{\circ} \mathrm{C}$, kept for $1 \mathrm{~h}$. The temperature was then brought back to $T_{f}$, kept for $3 \mathrm{~h}$, during which the catalytic activity was measured. The cycles were repeated for at least three times.

\section{3 - RESULTS AND DISCUSSION}




\section{1 - Principles of the FP technique}

In Fig.2 a schematic representation of the main steps of the FP synthesis is reported. The liquid solution containing the precursor salts is fed at constant flow rate through the capillary needle, ending $0.5 \mathrm{~mm}$ above the nozzle discharge mouth, so that the liquid droplets are instantaneously dispersed by the oxygen flow. Very small droplets are so formed, whose size depends mainly on liquid and oxygen flow rate and linear velocity. Extensive studies have been carried out by Mädler et al. [39], who concentrated on the first zone of the flame, trying to model droplets dispersion and size through correlations between proper adimensional parameters. Good dispersion and short droplets lifetime were observed by using oxygen (as in the present case) rather than air as dispersant/oxidant in the main nozzle. It should be taken into account that too large droplets could have a life-time higher than the residence time in the hottest zone of the flame, leading to non-uniform particle size [23].

The mechanism of product formation tightly depends on the particular system under study. Solvent volatility is a key parameter. If the solvent readily evaporates, products formation proceeds via monomer or clusters formation as in aerosol processes (see e.g. $\mathrm{ZrO}_{2}$ synthesis reported in [25]). By contrast, if solvent evaporation is slow, egg-shell hollow particles can form, possibly breaking down due to the explosive evaporation of the residual solvent inside them $[25,28,32]$. This phenomenon can be observed with fusible precursors even in the case of rapid solvent evaporation, as e.g. in $\mathrm{Bi}_{2} \mathrm{O}_{3}$ preparation [22].

At longer distance from the nozzle mouth, the presence of primary solid particles only can be hypothesised. After this point the main steps are coalescence, depending on collisions between the particles, and sintering. The former phenomenon can be limited by decreasing particles concetration in the flame, though lowering productivity. On the other hand, extensive sintering can be avoided by lowering flame temperature and particle 
residence time in the hottest zone. This parameter can be modulated in two different ways: a) by shortening flame height through a proper selection of $\mathrm{O}_{2}$ feeding flow rate and $b$ ) by increasing $\mathrm{O}_{2}$ linear velocity.

This schematic representation (Fig.2) summarises some of the main parameters influencing SSA and particle size of the product, which ultimately affect catalytic activity and thermal stability.

\section{2 - Optimisation of the FP apparatus}

Our FP apparatus was set-up after the schematic drawing reported in [39]. The main difference is the closed powder collection section, including the electrostatic precipitator (Fig.1), allowing also a substantial reduction of the noise due to the jet flame nozzle. Furthermore, the addition of the air-supplying-nozzles large ring, surrounding the flame, helps in better conveying the powder to the recovery section and eases the full combustion of the organic matter, virtually eliminating any carbonaceous residua.

A first burner was built with a coaxial ring $(20 \mathrm{~mm}$ in diameter) of twelve vertical flamelets, similar to that reported in [39]. This however led to a very unstable flame. A substantial improvement of flame stability and of homogeneity of the catalyst particle size was obtained by reducing the diameter of the ring of flamelets and pointing them towards the core of the nozzle.

\section{3 - Effect of nozzle operating parameters on catalyst physical-chemical properties}

The FP technique is very versatile, the properties of the prepared material depending on many different parameters, sometimes contrasting with each other. The following are the most representative: 
1. $\mathrm{O}_{2}$ and $\mathrm{CH}_{4}$ flow rate to the supporting flamelets

2. $\mathrm{O}_{2}$ flow rate to the main nozzle

3. organic liquid solution flow rate

4. concentration of precursors in organic liquid solution

5. pressure drop across the nozzle and nozzle geometry

6. nature of the organic solvent and of metal precursor

In the present paper we report on the analysis of only some of them, namely $\mathrm{O}_{2}+$ $\mathrm{CH}_{4}$ gas mixture composition and flow rate for the supporting flamelets, concentration of the oxide precursors and flow rate of the liquid solution, $\mathrm{O}_{2}$ flow rate and pressure drop across the main nozzle.

\section{a) $\mathrm{O}_{2} / \mathrm{CH}_{4}$ gas mixture for the supporting flamelets}

The essential role of the ring of flamelets is to support and constantly ignite the main flame. At first a stoichiometric mixture of $\mathrm{CH}_{4}+$ air was employed, leading to poor flame stability when the pyrex cap of the conveyer to the electrostatic precipitator was put in place. The problem was readily overcome by substituting oxygen for air.

As for the $\mathrm{O}_{2} / \mathrm{CH}_{4}$ feeding ratio, an excess of $\mathrm{O}_{2}$ showed detrimental in any case, leading to a progressive shortening of the flamelets when increasing their flow rate until extinction. A stoichiometric feeding ratio showed by far preferable.

The flamelets overall gas flow rate showed ininfluent on products properties. Hence, for fuel and oxygen economy, the lowest feeding rate $\left(1 \mathrm{l} / \mathrm{min}\right.$ of $\mathrm{O}_{2}$ and $0.5 \mathrm{l} / \mathrm{min}$ of $\left.\mathrm{CH}_{4}\right)$, allowing to obtain a stable and compact crown of flamelets, was chosen.

\section{b) Liquid flow rate}

Ceteris paribus, the productivity of the system is proportional to liquid flow rate. Hence, in principle, the latter should be as high as possible. However, the higher the flow 
rate, the higher is the concentration of the forming powder in the flame, so increasing the frequency of particle collision and sintering. Hence, if the goal is to obtain high surface area (i.e. poorly agglomerated products), a compromise has to be found between productivity and particle size.

Liquid flow rate was here varied, either by keeping the $\mathrm{O}_{2} /$ liquid feeding ratio $\left(\Phi=\frac{\left(\mathrm{molO}_{2} / \mathrm{mol} \text { fuel }\right)_{\text {real }}}{\left(\mathrm{mol} \mathrm{O}_{2} / \mathrm{mol} \text { fuel }\right)_{\text {stoich }}}\right)$ at constant value $(\Phi=2)$, or by increasing liquid flow rate at constant $\mathrm{O}_{2}$ feeding rate $(5 \mathrm{l} / \mathrm{min})$. In the former case, the flame height remained constant (ca. $4 \mathrm{~cm}$ ) and no significant change of product SSA was observed. Indeed, by increasing the solution flow rate from 0.97 to $4.4 \mathrm{~cm}^{3} / \mathrm{min}$, the BET surface area was always ca. 55 $\mathrm{m}^{2} / \mathrm{g}$ (Fig.3). Under these conditions the particles concentration in the flame increases, but their residence time within the flame decreases. These effects compensate each other, leading to a constant particle size. By contrast, when the liquid feeding rate was increased (vide supra) by keeping constant the $\mathrm{O}_{2}$ flow rate at a value exceeding the stoichiometric one, productivity raised, together with flame height. However, a progressive drop of product surface area (from 70 to $41 \mathrm{~m}^{2} / \mathrm{g}$ ) was observed (Fig.3). This is due to the increase of particles concentration within the flame.

It can be concluded that, if the goal is a high-productivity preparation of highly sintered materials, liquid flow rate has to be enhanced by keeping constant the $\mathrm{O}_{2}$ feeding rate. By contrast, the productivity of high surface area catalysts can be improved by increasing the solution flow rate, while keeping constant the $\mathrm{O}_{2} /$ liquid feeding ratio.

\section{c) Concentration of the precursors solution}

Obviously, the higher the precursors concentration, the higher is the amount of powder produced per unit time. Hence, to save time, solvent, $\mathrm{O}_{2}$ and auxiliary gases, highly concentrated solutions are preferable, of course within the precursors solubility 
limits. However, when increasing the precursors concentration beyond a given limit, a noticeable drop of surface area can be observed (Fig.4). This is due to an increased concentration of primary particles in the flame, which favours particles collision frequency and sintering. Furthermore, an increased availability of precursors could enhance also sintering in gas phase, so leading to particles necking. Hence, in order to prepare smallsize, high surface area particles, diluted solutions are preferable, by increasing productivity through liquid flow rate adjustment at constant $\Phi$ (vide supra). The first point in Fig.4, i.e. for a concentration of $0.025 \mathrm{M}$, is due to the formation of too small primary particles, which more easily sinter in the hottest zone of the flame.

A tentative calculation of the theoretical size of a particle can be done by hypothesising an instantaneous evaporation of the solvent of a single droplet. The resulting particle should have a diameter, $D_{p}$, given by:

$$
D_{p}=D_{d} \sqrt[3]{M \cdot N_{A} \cdot V_{u c} / Z}
$$

where $D_{d}$ is the droplet diameter, $M$ is the molar concentration, $N_{A}$ is the Avogadro's number, $V_{u c}$ is the crystal unit cell volume $\left(336.13 \AA^{3}\right.$ for $\left.\mathrm{LaCoO}_{3}\right)$ and $Z$ the number of molecules per unit cell (6 for $\left.\mathrm{LaCoO}_{3}\right)$.

For $D_{d}=4 \mu \mathrm{m}$, a reasonable value for a spray droplet, and $M=0.1 \mathrm{~mol} / \mathrm{l}$, the resulting $D_{p}$ should be $600 \mathrm{~nm}$, rather far from our experimental evidence of BET average particles diameter $\left(D_{B E T}\right) \approx 12-20 \mathrm{~nm}\left(D_{B E T=6 / S S A} \rho\right.$ and $\rho=7,29 \mathrm{~g} / \mathrm{ml}$ for $\left.\mathrm{LaCoO}_{3}\right)$. In other words the droplets diameter should be unreasonably low (by 1 or 2 orders of magnitude) to lead to the observed $D_{B E T}$ value. Therefore, it can be concluded that our product particles derive from secondary droplets forming through dispersion of the primary ones by oxygen. Alternatively, small particles could form by breaking of primary hollow particles, due to evaporation of the encapsulated residual solvent [28,32], a less probable possibility in the present case. 
d) $\mathrm{O}_{2}$ linear velocity

A preliminary study of the nozzle was carried out to determine its main working parameters, such as the discharge coefficient $C$ and the equivalent discharge section $\left(A_{\text {eq }}\right)$, from which one may determine the $\mathrm{O}_{2}$ linear speed in the nozzle throat under different working conditions.

The mass flow rate of discharge $(w)$ of a perfect gas from a nozzle under sub-critical (subsonic) flow conditions can be calculated from the following equation [41]:

$$
w=C Y A_{2} \sqrt{\frac{2 g_{c}\left(p_{1}-p_{2}\right) \rho_{1}}{1-\beta^{4}}}
$$

where $C$ is the discharge coefficient, which is a function of Reynolds number $(R e)$ and nozzle geometry, $A_{2}$ the cross-section area of the throat, $p_{1}$ and $p_{2}$ the upstream and downstream pressure, respectively, $\beta$ the nozzle throat to adduction conduit diameter ratio and $Y$ is the expansion factor. For gaseous fluids $Y$ is given by:

$$
Y=\sqrt{r^{2 k}\left(\frac{k}{k-1}\right)\left(\frac{1-r^{(k-1) / k}}{1-r}\right)\left(\frac{1-\beta^{4}}{1-\beta^{4} r^{2 / k}}\right)}
$$

where $r$ is the pressure ratio $p_{2} / p_{1}$ and $k$ is the specific heat ratio $c_{p} / c_{v}$.

Raising the absolute upstream pressure $p_{1}$, the discharge velocity from the nozzle increases, until it attains and then overcomes the speed of sound, when the upstream pressure gets over a critical value and the geometry of the nozzle becomes convergentdivergent. At the critical value the pressure ratio assumes its minimum value $\left(r_{c}\right)$ and the actual pressure in the throat will not fall below $p_{1} r_{c}$, even if a much lower pressure exists downstream. Under critical flow conditions, the mass flow rate of discharge ( $\left.w_{\max }\right)$ of a perfect gas can be calculated by the following equation [41]:

$$
w_{\max }=C A_{2} p_{1} \sqrt{g_{c} k\left(\frac{M}{R T_{1}}\right)\left(\frac{2}{k+1}\right)^{(k+1) /(k-1)}}=K C A_{2} p_{1}
$$


where $g_{c}=980 \mathrm{~cm} / \mathrm{s}^{2}, M$ is the gas molecular weight; $T_{1}$ the gas temperature $(\mathrm{K})$ in the upstream side of the nozzle and $R$ the gas constant. For oxygen $k=1.396$ and $r_{c}=0.528$ and at room temperature Eq. (3) becomes:

$w_{\max }=14.5 \cdot C A_{2} p_{1}$

where $w_{\max }$ is expressed in $\mathrm{g} / \mathrm{min}, A_{2}$ in $\mathrm{mm}^{2}$ and $p_{1}$ in bar.

Eq. (1) shows that the mass flow rate under subsonic condition is proportional to $p_{1}^{1 / 2}$, while at the sonic regime it is directly proportional to $p_{1}$ (Eq. 4).

At last, a simple equation to calculate the discharge velocity $\left(u_{2}\right)$ from a convergentdivergent nozzle, given the upstream $\left(p_{1}\right)$ and downstream $\left(p_{2}\right)$ pressure and the critical velocity in the throat $\left(u_{c}\right)$, is the following [41]:

$\left(\frac{u_{2}}{u_{c}}\right)^{2}=\left(\frac{k+1}{k-1}\right)\left[1-\left(\frac{p_{2}}{p_{1}}\right)^{(k-1) / k}\right]$

First a series of experimental data was collected (Fig.5) for several different nozzle geometries (openings), by keeping constant at $5 \mathrm{Nl} / \mathrm{min}$ the value of $\mathrm{O}_{2}$ flow rate and varying the pressure drop $\Delta P$ across the nozzle (Table 1 ).

The discharge coefficient $C$ may be calculated in two ways, i.e. through Eq.1 or through Eq.4. As an example we report the calculation of $C$ for the maximum nozzle opening (Fig.5, curve a).

Following the first way, an $\mathrm{O}_{2}$ flow rate of $5 \mathrm{NI} / \mathrm{min}(6.65 \mathrm{~g} / \mathrm{min})$ corresponds to an upstream pressure of $1.3 \mathrm{bar}$, lower than the critical pressure (1.8 bar). Hence, the relationship between $w$ and $p_{1}$ can be calculated by Eq. (1), applicable to sub-sonic flow conditions, provided that $Y$ has been calculated through Eq. (2). Our nozzle has a crown circular cross-section area $A$, so that to calculate $\beta$ we introduce an equivalent diameter $\left(D_{e}=\sqrt{\frac{4 A}{\pi}}\right)$, from which $\beta=\frac{D_{e 2}}{D_{e 1}}=\sqrt{\frac{A_{2}}{A_{1}}}=0.23, A_{1}$ being the cross section area of the 
nozzle upstream conduit, before the throat. Then, from Eq.2, we get $Y=0.87$ and, from Eq. $1, C=0.41$ (at r.t.)

Following the second way, referring to sonic flow rate (Eq.4), the slope (14.5CA2) of the linear part of the Fig.5 experimental curves is proportional to the cross-section area of the so-called vena contracta $\left(C A_{2}\right)$. Then, for the known value of $A_{2}=0.98 \mathrm{~mm}^{2}$, from the slope of the straight line portion of curve $a$ (Fig.5 and Table 1) a value of $C=\frac{\text { Slope }}{14.5 \cdot A_{2}}=\frac{\text { Aeq }}{A_{2}}=\frac{0.418}{0.98}=0.42$ was obtained.

The $\mathrm{O}_{2}$ discharge velocity can then be easily calculated as actual flow rate in the throat ( $\left.V_{\max }\right)$ divided by the equivalent cross-section area $\left(A_{e q}\right)($ Table 1$)$.

Nozzle geometry is represented in Fig.6, showing how the configuration can be shifted from convergent to convergent-divergent by simply moving vertically the inner part of the burner set. For a convergent nozzle (Fig.6a) the highest obtainable discharge velocity is sonic, i.e. $341 \mathrm{~m} / \mathrm{s}$, while for the convergent-divergent geometry (Fig.6b) a supersonic velocity can be attained.

$\mathrm{O}_{2}$ velocity was here varied at constant $\mathrm{O}_{2}$ flow rate, by progressively narrowing the nozzle discharge section, therefore increasing the pressure drop across the nozzle from 0.3 to 7 bar. The effect of $\mathrm{O}_{2}$ discharge velocity on catalyst SSA is reported in Fig.7. At first, under subsonic discharge conditions, an increase of SSA can be observed. When sonic velocity was reached, a further increase of $\mathrm{O}_{2}$ pressure drop did not entrain an increase of SSA, which remained constant, being constant the discharge linear velocity. Then, by progressively narrowing the nozzle discharge section, its geometry changed into convergent-divergent, allowing to increase $\mathrm{O}_{2}$ linear velocity over the sonic value and hence the SSA of the product further increased. These data were confirmed by XRD analysis, which showed a progressively lower powder crystal size with increasing $\mathrm{O}_{2}$ 
velocity. However, when sonic discharge conditions were kept constant, the XRD line broadening (powder crystal size) remained fairly constant.

$\mathrm{O}_{2}$ linear velocity mainly determines the residence time of the primary particles in the flame. The lower the residence time, the lower is particles sintering and hence the higher is SSA. However, a too low residence time into the flame could lead to insufficient thermal resistance of the powder. Moreover, the permanence of the precursor into the flame has to be sufficient to permit its complete conversion into the desired perovskitic phase and the complete combustion of the organic compounds (solvent and precursors anions). $\mathrm{O}_{2}$ velocity can be modelled throughout the flame as reported e.g. in [23], showing an increase of velocity immediately after the nozzle mouth (up to ca. $1.5 \mathrm{~cm}$ ) due to combustion, followed by asymptotic deceleration, as in cold jets, as a function of $1 / x, x$ being the distance from the nozzle.

An increase of $\mathrm{O}_{2}$ velocity also determines a decrease of flame height, as shown in Fig.8, so affecting the residence time into the flame. Therefore, $\mathrm{O}_{2}$ velocity has a double influence on this fundamental parameter. Furthermore, images (here not reported) taken with a high-speed infrared camera, suggested a transition from laminar to turbulent flow regime when increasing pressure drop (and hence $\mathrm{O}_{2}$ velocity) from 0.3 to 6 bar, evidenced by the formation of vortices. This affected noticeably SSA, which increased from 42 to $66 \mathrm{~m}^{2} / \mathrm{g}$. However, the deepest impact was observed on particle size distribution (Fig.9). With a laminar flow regime, a poor size uniformity was obtained, SEM micrographs showing the presence of large spheres together with much smaller particles (Fig.9a). By contrast, in turbulent flow regime a much higher size uniformity was reached (Fig. 9b), the product consisting of nanospheres, ca. $20 \mathrm{~nm}$ in diameter. This can be explained when considering the gas velocity profile under laminar and turbulent flow conditions. In the former regime particle residence time into the hottest part of the flame is different for a primary particle in the jet core, with respect to that of a particle in the 
periphery of the jet and no efficient mixing can occur. Under turbulent conditions the much more efficient mixing leads to uniform residence time in any part of the jet, preventing any extensive sintering of the particles. A similar behaviour was observed during the preparation of $\mathrm{V}$-Ti oxide through aerosol flame synthesis [30].

\section{e) $\mathrm{O}_{2}$ flow rate}

$\mathrm{O}_{2}$ flow rate was first varied at constant nozzle discharge section, so to have an increasing pressure drop across the nozzle. By raising $\mathrm{O}_{2}$ flow rate, starting from subcritical conditions, an increase of $\mathrm{O}_{2}$ linear velocity was observed, until critical pressure and hence sonic discharge velocity were attained (vide supra). SSA of the powder was found to rapidly increase with increasing $\mathrm{O}_{2}$ flow rate (and velocity) (Fig 10, full line). After the sonic regime was attained, some marginal increase of SSA was observed, but much less marked than under subsonic conditions.

The dependence of SSA, and hence of particle size, on $\mathrm{O}_{2}$ flow rate is rather complex. With constant nozzle geometry and under subsonic conditions, an increase of $\mathrm{O}_{2}$ flow rate brings about an increase of its linear velocity. Therefore, an increase of SSA can be surely attributed to the above mentioned causes, i.e. a faster transport of the primary particles through a progressively shorter flame, which prevents any significant particle sintering. However, increasing oxygen flow rate at constant liquid feeding rate leads also to a higher dispersion degree of the particles within the flame, decreasing the probability of collision between them. Furthermore, $\mathrm{O}_{2}$ has also a quenching effect, lowering the flame temperature and hence particle sintering rate.

All these effects are hardly enucleable from each other, so another set of samples was prepared, trying to eliminate the effect of residence time on SSA and particle size. For this purpose we varied the $\mathrm{O}_{2}$ flow rate, but keeping constant the pressure drop through the nozzle at a value higher than the critical pressure. This corresponds to sonic discharge 
conditions and hence to constant $\mathrm{O}_{2}$ velocity, independently of $\mathrm{O}_{2}$ flow rate. By increasing the latter, a small increase of surface area was observed (Fig.10, dashed line), exclusively due to the quenching effect of oxygen and to the decrease of particle concentration into the flame. As expected, the two curves overlapped (Fig.10) when sonic conditions occurred in both cases.

It may be concluded that $\mathrm{O}_{2}$ flow rate is a very critical parameter, allowing or not to obtain the desired product, apart from its actual physical properties. Indeed, when the $\mathrm{O}_{2}$ flow rate was too high with respect to the liquid flow rate, i.e. higher than $8 \mathrm{l} / \mathrm{min}$, corresponding to $\Phi>3$, the quenching effect was excessive, so inhibiting the formation of a highly crystalline perovskitic phase. The effect of this parameter on sample crystallinity is shown in Fig.11, which qualitatively depicts the decrease of crystal size with increasing $\mathrm{O}_{2}$ flow rate.

\section{3 - Effect of nozzle operating parameters on catalytic activity}

The present samples were tested as catalysts for the CFC of methane. As expected, catalytic activity increased with increasing SSA, provided that a pure perovskitic phase was obtained. Catalytic performance was essentially intrafacial [1,2], as already reported for $\mathrm{LaCoO}_{3}$ samples $[8,13,42]$. In principle, high SSA should enhance suprafacial activity, i.e. it should increase the reactivity due to available surface oxygen. Conversely, intrafacial activity should be more tied to oxygen mobility through the bulk. Oxygen mobility for undoped perovskitic systems is ultimately due to lattice disorder, i.e. to the presence of vacancies, allowing oxygen jumping between them with low activation energy. Therefore, synthesis conditions allowing small crystal size (i.e. high SSA) could enhance also bulk oxygen mobility. 
As an example, the dependence of catalytic activity on pressure drop $(\Delta p)$ across the nozzle, and hence on $\mathrm{O}_{2}$ discharge velocity, is reported in Fig.12. It can be observed that raising $\Delta p$ allows to enhance noticeably catalytic activity, in line with the observed parallel increase of SSA. Indeed, the temperature of methane half conversion ( $\left.T_{1 / 2}\right)$ decreased from 437 to 404 and to 383 for $\Delta p$ of $0.3,1,5$ and 6 bar, respectively.

From these activity data we can conclude that the FP technique allows to obtain highly active catalysts, which completely convert methane fairly below $550^{\circ} \mathrm{C}$. These results are comparable with those previously reported for some of the most active perovskitic samples obtained through other preparation techniques $[7,12,13]$ and with those of noble metal-based catalysts for the same reaction.

\section{4 - Effect of nozzle operating parameters on catalyst thermal stability}

The CFC of methane requires a thermally highly resistant catalyst, due to the elevated working temperature. A flame-based preparation technique can fulfil this requirement, entraining a fast calcination of the powder at high temperature $\left(>1000^{\circ} \mathrm{C}\right)$. Thermal resistance of the present catalysts was checked both after a prolonged working time $(48 \mathrm{~h})$ and after cycles of accelerated deactivation at $800^{\circ} \mathrm{C}$. Once a pure perovskitic phase was formed, catalyst durability always increased with decreasing SSA. A first example is reported in Fig.13, showing the dependence of this parameter for samples prepared at different pressure drop across the nozzle, and hence at different $\mathrm{O}_{2}$ linear velocity. As previously mentioned, the lower the pressure drop, the lower is $\mathrm{O}_{2}$ velocity, and hence the higher the reagents residence time into the flame, leading to more sintered, lower SSA materials. This reflects on thermal stability, which was higher for the samples prepared at lower $\mathrm{O}_{2}$ velocity. Indeed, for the sample prepared at a pressure drop of 0.3 bar, the residual $\mathrm{CH}_{4}$ conversion after the third deactivation cycle was still ca. $92 \%$, much 
better than that of the sample synthesised with a pressure drop of 6 bar, which lost ca. $50 \%$ of its activity. Hence, as expected, in order to improve thermal stability one needs to increase particle sintering, though at the expenses of a lower activity.

The same behaviour was shown by samples prepared with different $\mathrm{O}_{2}$ flow rates, as reported in Fig.14. Also in this case, an increase of $\mathrm{O}_{2}$ flow rate from 3 to $5 \mathrm{I} / \mathrm{min}$ brought about an increase of SSA from 32 to $56 \mathrm{~m}^{2} / \mathrm{g}$ (vide supra) due to many concomitant effects (increased $\mathrm{O}_{2}$ speed and hence decrease of residence time into the flame, higher quenching, lower concentration of the primary particles in the flame). This reflected in a much lower thermal stability of the catalyst, which lost $50 \%$ of its activity even after the first deactivation cycle, when prepared with $5 \mathrm{l} / \mathrm{min}$ of oxygen.

\section{Inserire commenti fig 15 (BET e SEM del calcinato)}

\section{CONCLUSIONS}

A spray FP apparatus was set up for the preparation of mixed oxides of perovskitic structure. Some different burner configurations were tested in order to optimise efficiency, flame stability and to reduce noise due to the jet flame. The effect of some nozzle operating parameters on phase purity, surface area and particle size of $\mathrm{LaCoO}_{3}$ test samples was investigated. A substantial increase of catalyst SSA can be obtained when decreasing the concentration of the feeding solution, though depressing productivity. The latter can be improved by increasing liquid flow rate, provided that the $\mathrm{O}_{2}$ /liquid feeding ratio is kept constant, so that SSA of the product is only marginally affected. A theoretical study on our nozzle allowed to determine the $\mathrm{O}_{2}$ discharge velocity and to observe how it affects SSA. The latter increases with increasing $\mathrm{O}_{2}$ speed under subsonic conditions, remains constant under sonic regime and finally increases again when a supersonic discharge velocity is reached. $\mathrm{O}_{2}$ flow rate was varied either by increasing pressure drop 
$(\Delta p)$ across the nozzle, or by varying the nozzle geometry at constant $\Delta p$. It was found that $\mathrm{O}_{2}$ flow rate deeply influences both particle size and crystallinity, due to several concomitant factors. Furthermore, as expected, any changes of catalyst properties deeply affect both catalytic activity for the CFC of methane and thermal resistance of the catalyst.

\section{REFERENCES}

[1] - J.L.G. Fierro, J.M.D. Tascòn, L.G. Tejuca, J. Catal. 93 (1985) 83.

[2] - R.J.H. Voorhoeve, J.P. Remeika, D.W. Johnson, Science 180 (1973) 62.

[3] - T. Seiyama, in: L.G. Tejuca, J.L.G. Fierro (Eds.), Properties and Applications of Perovskite-Type Oxides, Dekker, New York, 1993, p. 215.

[4] - Y. Teraoka, H.M. Zhang, N. Yamazoe, Chem. Lett. (1985) 1367.

[5] - Y. Teraoka, M. Yoshimatsu, N. Yamazoe, T. Seiyama, Chem. Lett. (1984) 893.

[6] - H.M. Zhang, Y. Shimizu, Y. Teraoka, N. Miura, N. Yamazoe, J. Catal. 121 (1990) 432

[7] - R.A.M. Giacomuzzi, M. Portinari, I. Rossetti, L. Forni, in: A. Corma, F.V. Melo, S. Mendioroz, J.L.G. Fierro (Eds.), Study of Surface Science and Catalysis, Vol. 130, Elsevier, Amsterdam, 2000, p. 197.

[8] - R. Leanza, I. Rossetti, L. Fabbrini, C. Oliva, L. Forni, Appl. Catal. B: Environ. 28 (2000) 55 .

[9] - V. Szabo, M. Bassir, A. Van Neste, S. Kaliaguine, Appl. Catal. B: Environ., 37 (2002) 175

[10] - US Pat. no.: 6,017,504 (2000), to Université Laval (Canada). 
[11] - V. Szabo, M. Bassir, A. Van Neste, S. Kaliaguine, Appl. Catal. B: Environ., 43 (2003) 81 .

[12] - E. Campagnoli, A. Tavares, L. Fabbrini, I. Rossetti, Yu.A. Dubitsky, A. Zaopo, L. Forni, Appl. Catal. B: Environ., 55 (2005) 133.

[13] - I. Rossetti, L. Forni, Appl. Catal. B: Environ., 33 (2001) 345.

[14] - L. Fabbrini, I. Rossetti, L. Forni, Appl. Catal. B: Environ., 44 (2003) 107.

[15] - L. Fabbrini, I. Rossetti, L. Forni, Appl. Catal. B: Environ., 56(3) (2005) 221.

[16] - L. Fabbrini, I. Rossetti, L. Forni, Appl. Catal. B: Environ., submitted.

[17] -W.R. Moser, J.D. Lennhoff, J.E. Cnossen, K. Fraska, J.W. Schoonover, J.R. Rozak, in: W.R. Moser, (Ed.), Advanced Catalysts and Nano structured Materials, Academic Press, New York, 1996, p. 535.

[18] - J. Long, S.J. Teichner, Rev. Hautes Temper. et Refract., 2 (1965) 47.

[19] - M. Formenti, F. Juillet, P. Meriaudeau, S.J. Teichner, P. Vergnon, J. Colloid and Interface Science, 39 (1) (1972) 79.

[20] - W.J. Stark, L. Mädler, S.E. Pratsinis, EP 1,378,489 A1 (2004), to ETH, Zurich.

[21] - H. Schultz, W.J. Stark, M. Maciejewski, S.E. Pratsinis, A. Baiker, J. Mater. Chem., 13 (2003) 2979.

[22] - L. Mädler, S.E. Pratsinis, J. Am. Ceram. Soc., 85 (7) (2002) 1713.

[23] - M.C. Heine, S.E. Pratsinis, Ind. \& Eng. Chem. Res., ASAP Article, web release date: March 24 2005.

[24] - R. Strobel, W.J. Stark, L. Mädler, S.E. Pratsinis, A. Baiker, J. Catal., 213 (2003) 296.

[25] -R. Mueller, R. Jossen, H.K. Kammler, S.E. Pratsinis, M.K. Akhtar, AIChE J., 50(12) (2004) 3085.

[26] - T. Tani, K. Takatori, S.E. Pratsinis, J. Am. Ceram. Soc., 87 (3) (2004) 365.

[27] - R. Strobel, S.E. Pratsinis, A. Baiker, J. Mater. Chem., 15 (2005) 605. 
[28] - W.J. Stark, L. Mädler, M. Maciejewski, S.E. Pratsinis, A. Baiker, Chem. Commun., (2003) 588.

[29] -R. Mueller, R. Jossen, S.E. Pratsinis, M. Watson, M.K. Akhtar, J. Am. Ceram. Soc., 87(2) (2004) 197.

[30] - W.J. Stark, K. Wegner, S.E. Pratsinis, A. Baiker, J. Catal., 197 (2001) 182.

[31] - R. Jossen, S.E. Pratsinis, W.J. Stark, L. Mädler, J. Am. Ceram. Soc., 88 (2005) 1388.

[32] - K.Y. Jung, Y.C. Kang, Mater. Lett., 58 (2004) 2161.

[33] - S. Kim, J.J. Gislason, R.W. Morton, X.Q. Pan, H.P. Sun, R.M. Laine, Chem. Mater., 16 (2004) 2336.

[34] - J. Marchal, T. John, R. Baranwal, T. Inklin, R.M. Laine, Chem. Mater., 16 (2004) 822.

[35] - T. Johannessen, S. Koutsopoulos, J. Catal., 205 (2002) 404.

[36] - J.M. Mäkelä, H. Keskinen, T. Forsblom, J. Keskiken, J. Mater. Sci.,39 (2004) 2783.

[37] - A. Kilian, T.F. Morse, Aerosol Sci. and Tech., 34 (2001) 227.

[38] - D.J. Seo, S.B. Park, Y.C. Kang, K.L. Choy, J. Nanoparticle Res., 5 (2003) 199.

[39] - L. Mädler, H.K. Kammler, R. Mueller, S.E. Pratsinis, J. Aerosol Sci., 33 (2002) 369.

[40] -Schoonover, J.R. Rozak, in: W.R. Moser, (Ed.), Advanced Selected Powder Diffraction Data, Miner. DBM (1-40), J.C.P.D.S., Swarthmore, PA, 1974-1992.

[41] - R.H. Perry, C.H. Chilton, Eds., Chemical Engineer's Handbook, $5^{\text {th }}$ Edition, Mc Graw Hill, New York, 1973.

[42] - E. Campagnoli, A.Tavares, L. Fabbrini, I. Rossetti, Yu.A.Dubitsky, A.Zaopo, L. Forni, J. Mater. Sci., in press. 


\section{TABLES}

Table 1: Main working parameters vs. pressure drop for a selected nozzle geometry $\left(\mathrm{O}_{2}\right.$ flow rate $=5 \mathrm{Nl} / \mathrm{min})$.

\begin{tabular}{|c|c|c|c|c|c|c|c|}
\hline $\boldsymbol{\Delta p}[\mathrm{bar}]$ & $\mathbf{0 . 3}$ & $\mathbf{0 . 6}$ & $\mathbf{1 . 2}$ & $\mathbf{3}$ & $\mathbf{4 . 5}$ & $\mathbf{6}$ & $\mathbf{7}$ \\
\hline $\mathbf{s l o p e}$ & 6.057 & - & 3.096 & 1.776 & 1.236 & 0.949 & - \\
\hline $\mathbf{A}_{\text {eq }}{ }^{*}\left[\mathbf{m m}^{2}\right]$ & 0.418 & 0.281 & 0.213 & 0.116 & 0.085 & 0.065 & - \\
\hline $\mathbf{p}_{1}[\mathrm{bar}]$ & 1.3 & 1.6 & 2.2 & 4.0 & 5.5 & 7.0 & 8.0 \\
\hline $\boldsymbol{V}_{\max }{ }^{\star \star}[\mathbf{l} / \mathbf{m i n}]$ & 5.00 & 5.00 & 4.27 & 2.40 & 1.72 & 1.35 & 1.18 \\
\hline $\boldsymbol{u}^{\star \star}[\mathbf{m} / \mathbf{s}]$ & 199 & 296 & 337 & 340 & 338 & 344 & 340 \\
\hline $\boldsymbol{u}_{\mathrm{o}}[\mathbf{m} / \mathbf{s}]$ & 199 & 296 & 337 & 340 & 338 & 550 & 564 \\
\hline
\end{tabular}

${ }^{*} A_{\text {eq }}=C \cdot A_{2}$

** in the nozzle throat

Table 2: Effect of the presently investigated operating parameters on some properties of the catalyst. 


\section{FIGURE CAPTIONS}

Fig.1: Scheme of the FP apparatus. A: burner, B: pyrex glass conveyor, C: multipin effluviator, D: collector, E: heating mantle.

Fig.2: Scheme of the principle of particle formation and growth into the flame.

Fig.3: Dependence of SSA on liquid flow rate. Open squares: constant (5NI/min) $\mathrm{O}_{2}$ flow rate; full triangles: constant $\mathrm{O}_{2} /$ liquid $(\Phi=2)$ feeding ratio.

Fig.4: Dependence of SSA on precursors concentration $\mathrm{M}(\mathrm{mol} / \mathrm{l})$ in the feeding solution.

Fig.5: Oxygen mass flow rate vs. nozzle upstream pressure $\left(p_{1}\right)$ for different nozzle geometries (openings) ensuring $5 \mathrm{Nl} / \mathrm{min}$ of oxygen volumetric flow rate with a pressure drop $\Delta p$ across the nozzle of: a) $0.3, b) 1.2, c) 3.0, d) 4.5, e) 6.0$ bar.

Fig.6: Schematic representation of nozzle geometry: a) convergent; b) convergentdivergent.

Fig.7: Dependence of SSA on pressure drop across the nozzle.

Fig.8: Flame height in laminar (left side) or turbulent (right side) regime.

Fig.9: SEM micrographs relative to samples prepared in laminar $(a, b)$ or turbulent $(c, d)$ regime.

Fig.10: $\mathrm{SSA}$ vs. $\mathrm{O}_{2}$ flow rate: at constant nozzle geometry (full line) or at constant pressure drop under sonic discharge conditions (dashed line).

Fig.11: Effect of $\mathrm{O}_{2}$ flow rate $(\mathrm{l} / \mathrm{min})$ on sample crystallinity.

Fig.12: Catalytic activity of samples prepared at different $\mathrm{O}_{2}$ pressure drop (bar) across the nozzle.

Fig.13: Thermal stability of samples prepared at different $\mathrm{O}_{2}$ pressure drop (bar) across the nozzle.

Fig.14: Thermal stability of samples prepared at different $\mathrm{O}_{2}$ flow rate $(1 / \mathrm{min})$. 
Fig.1

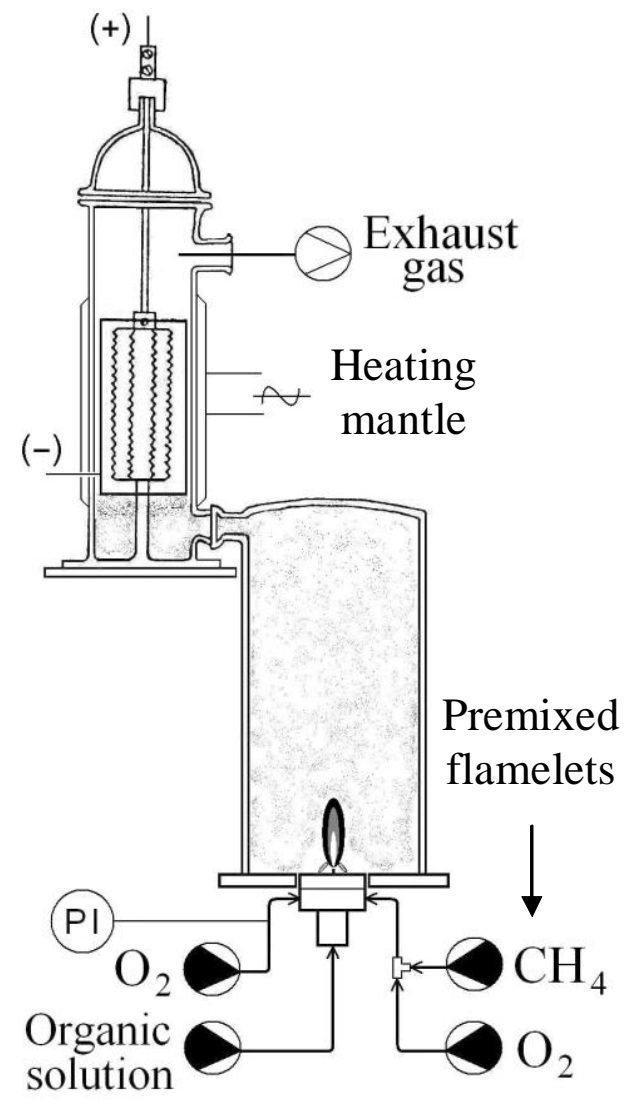

Fig.2

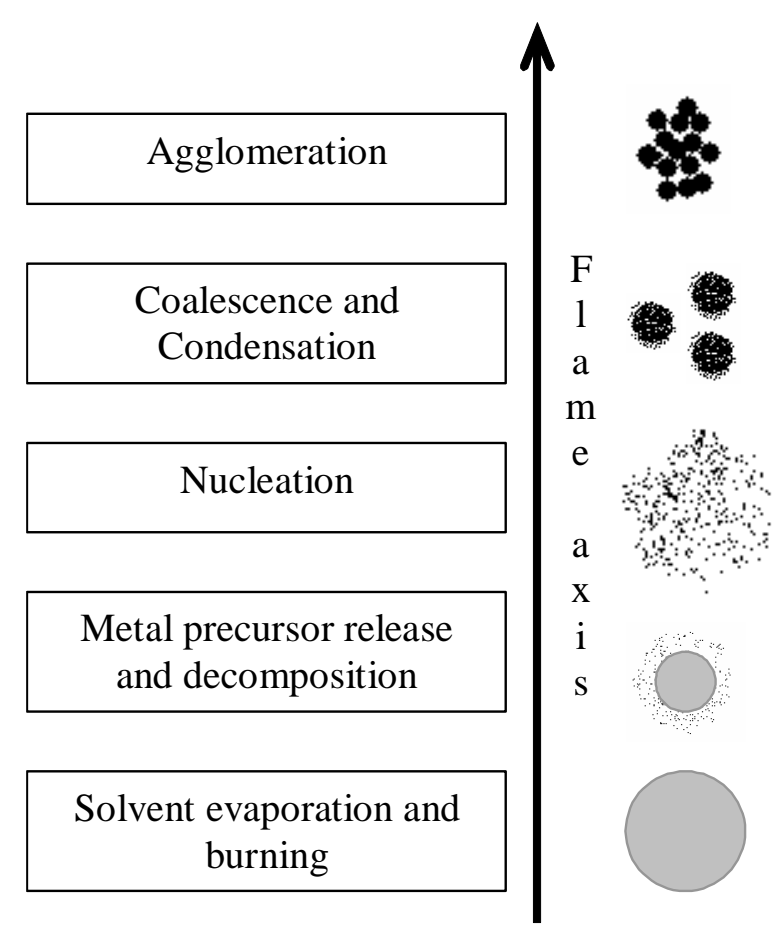


Fig.3

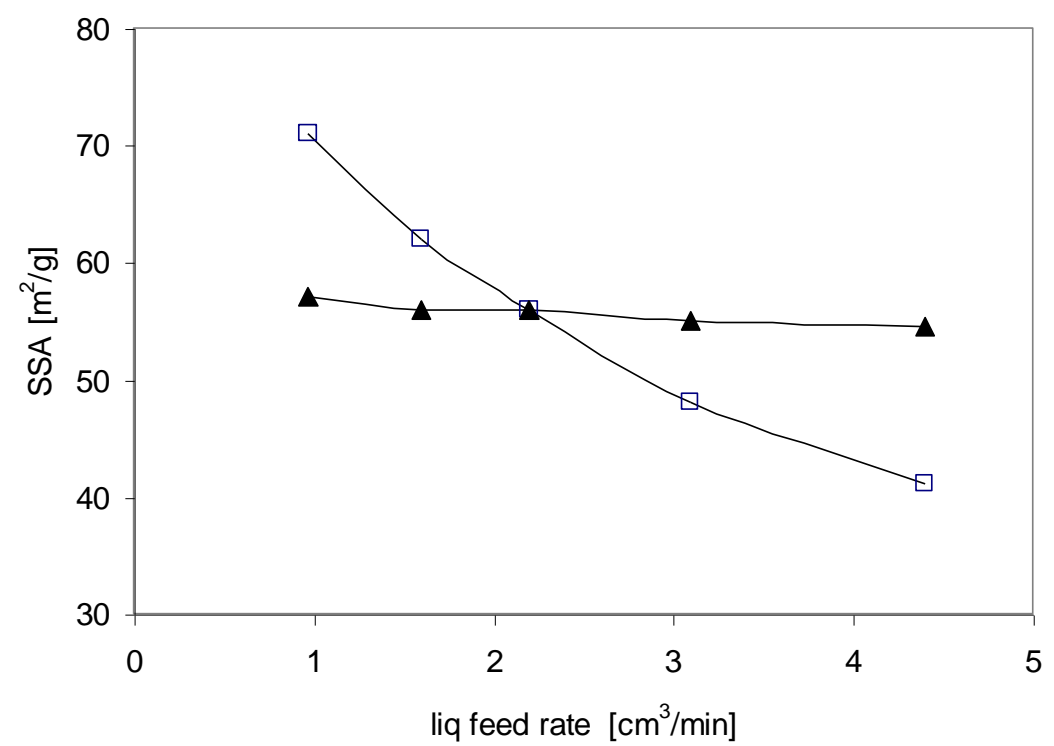

Fig.4

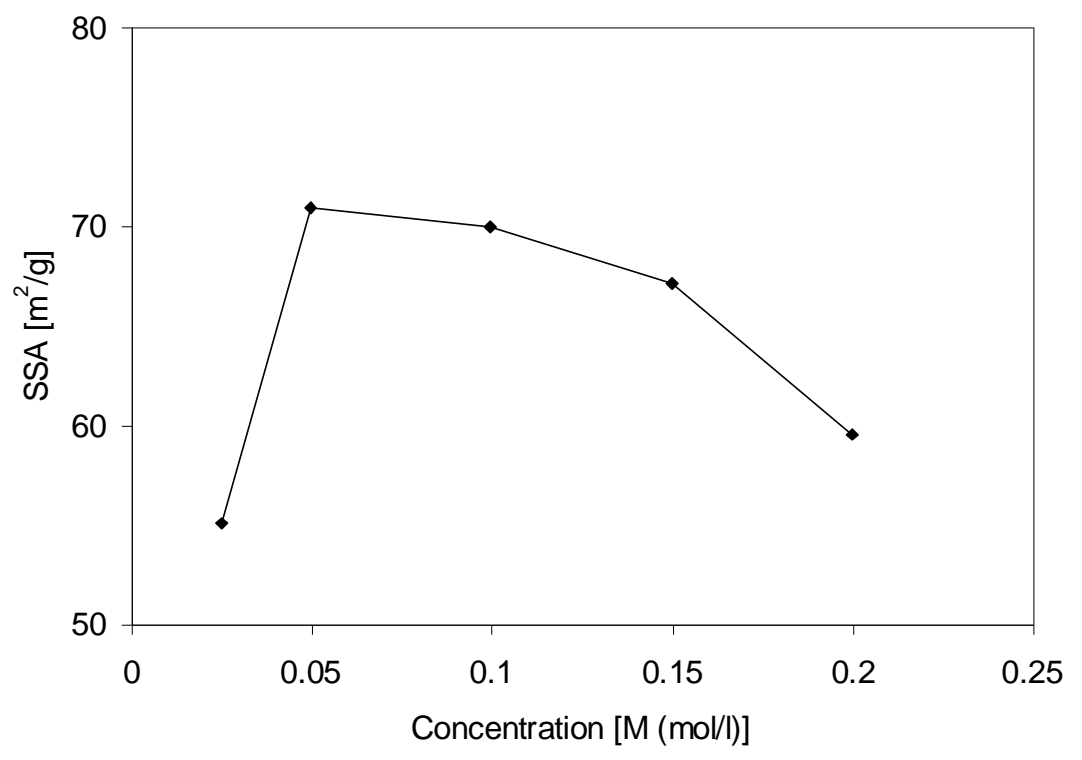


Fig.5

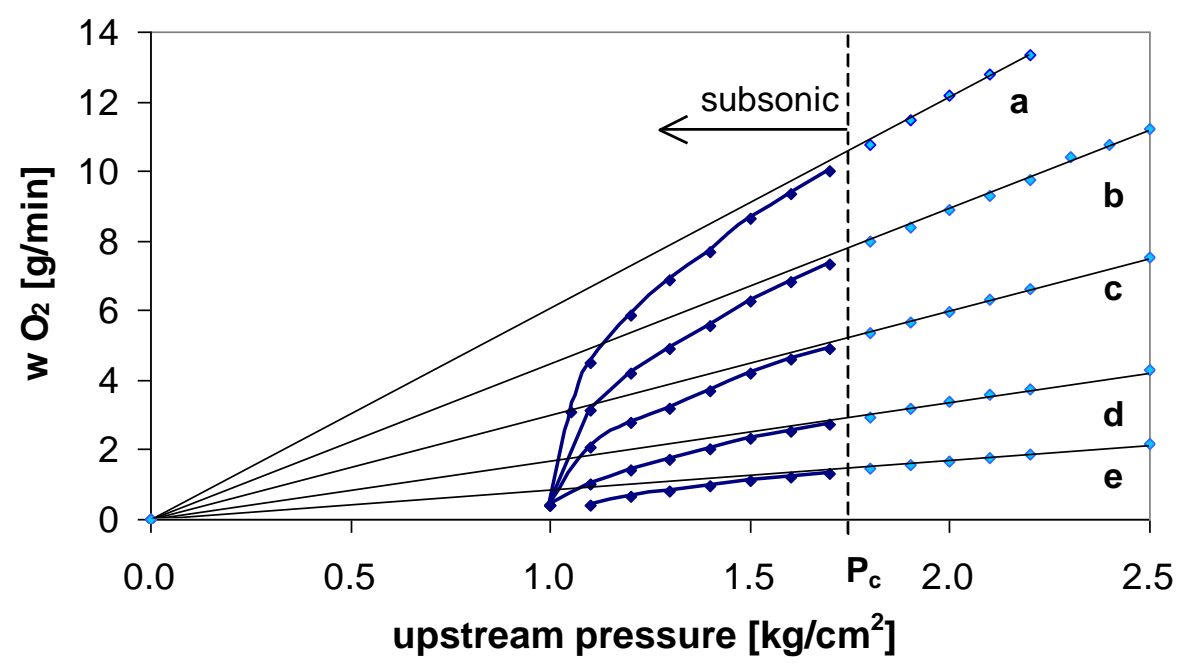

Fig.6
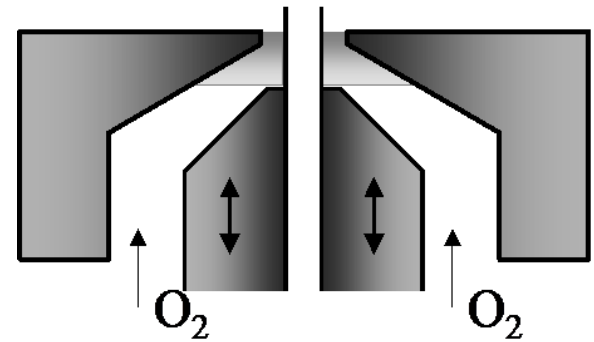

a
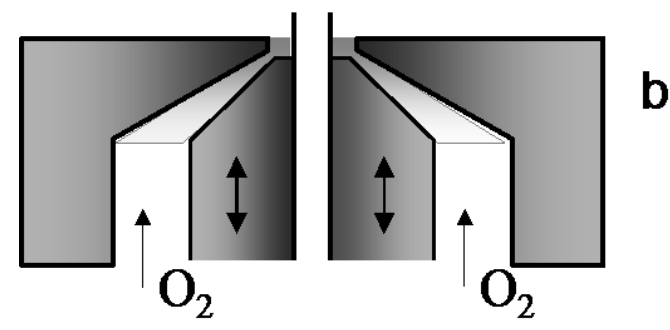
Fig.7

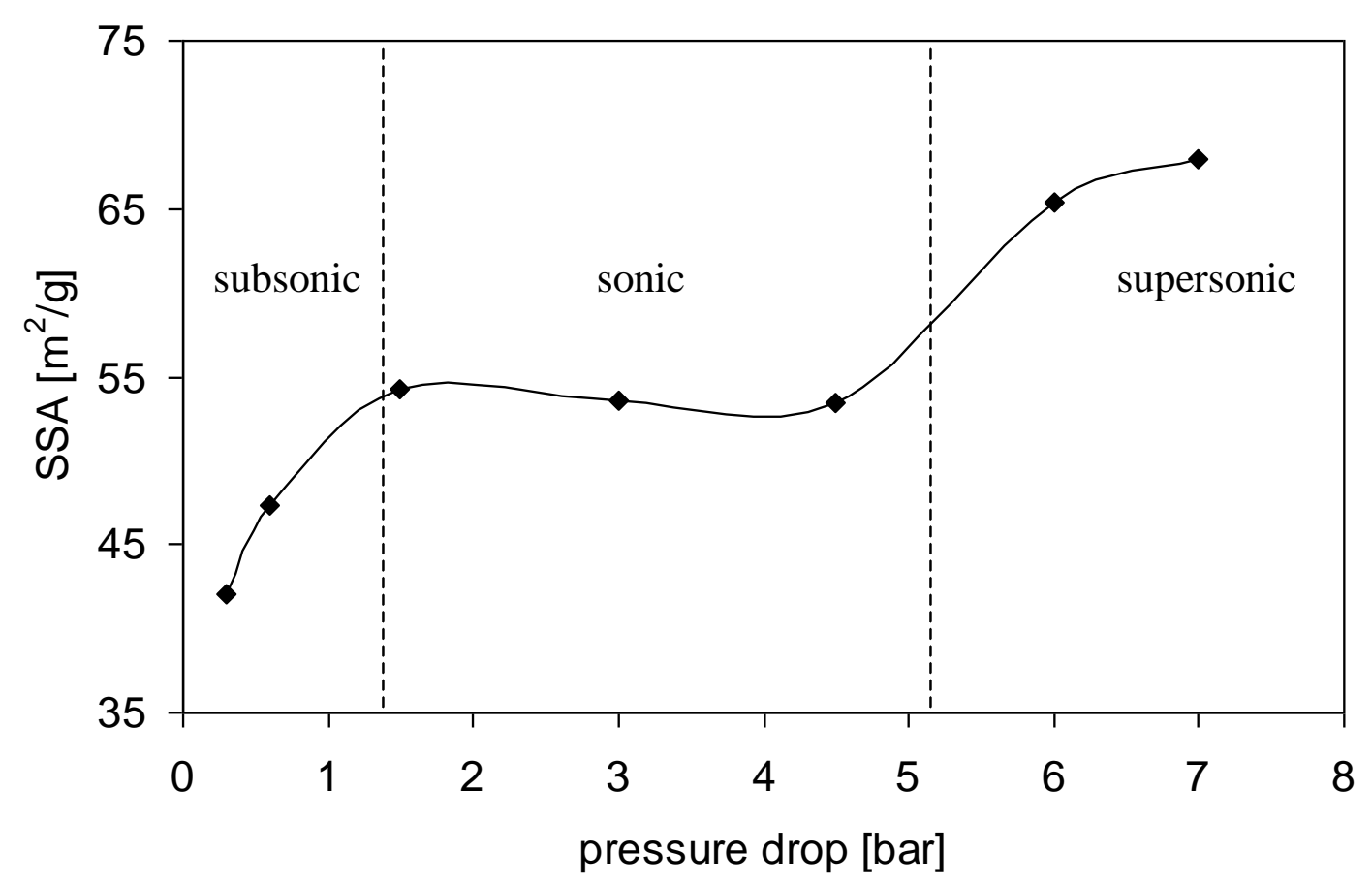

Fig.8
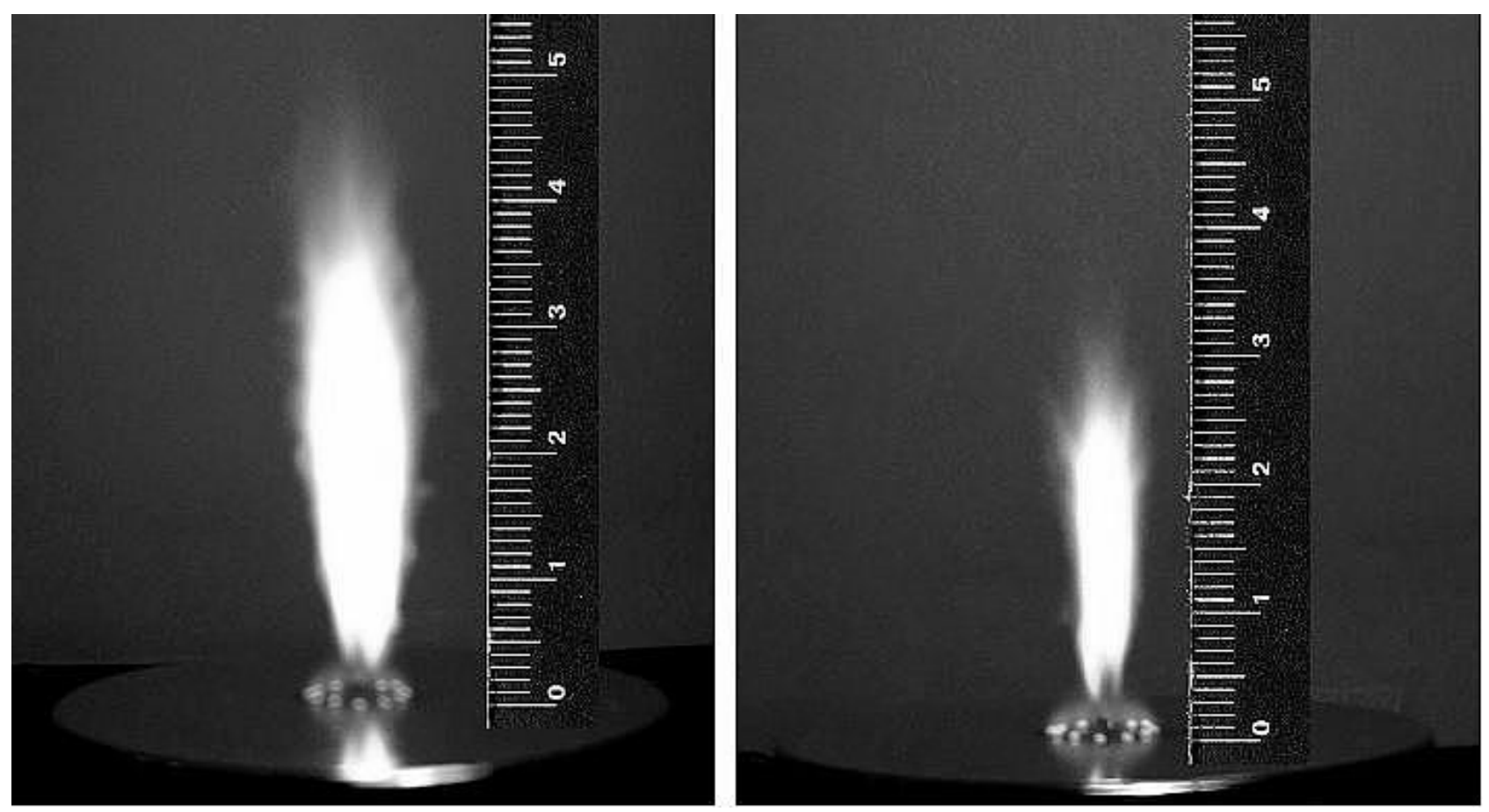
Fig.9
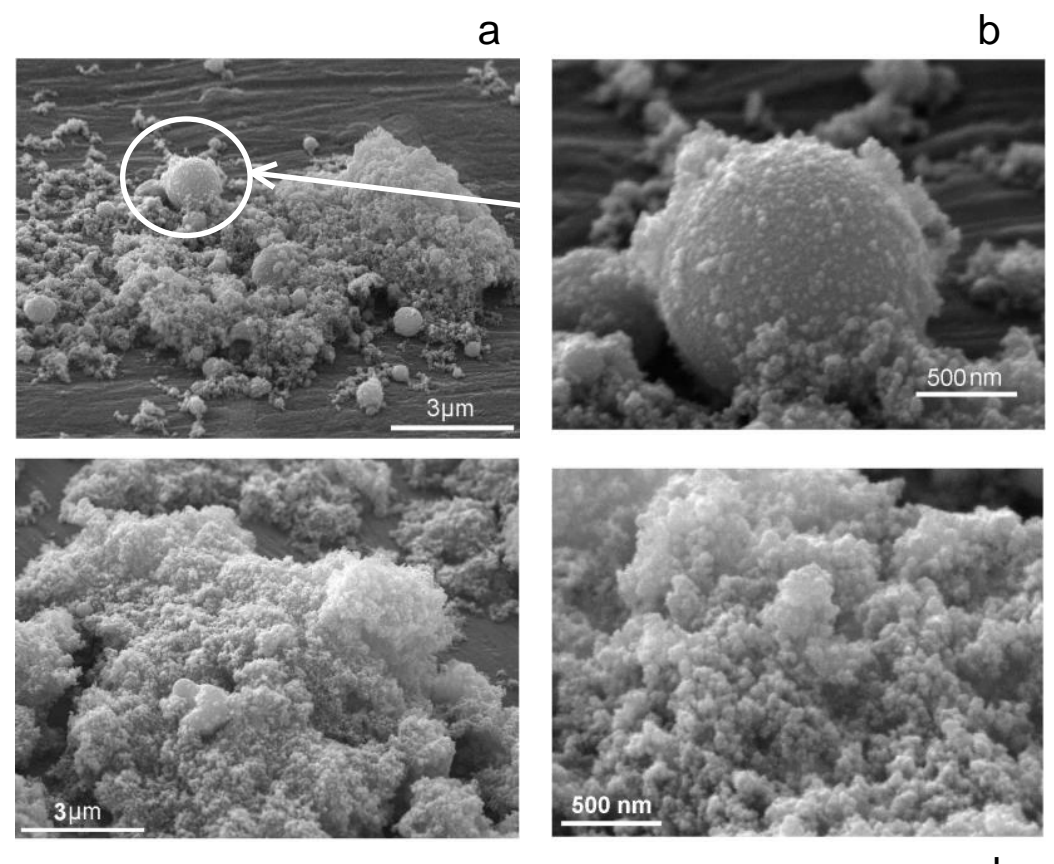

C

d

Fig.10

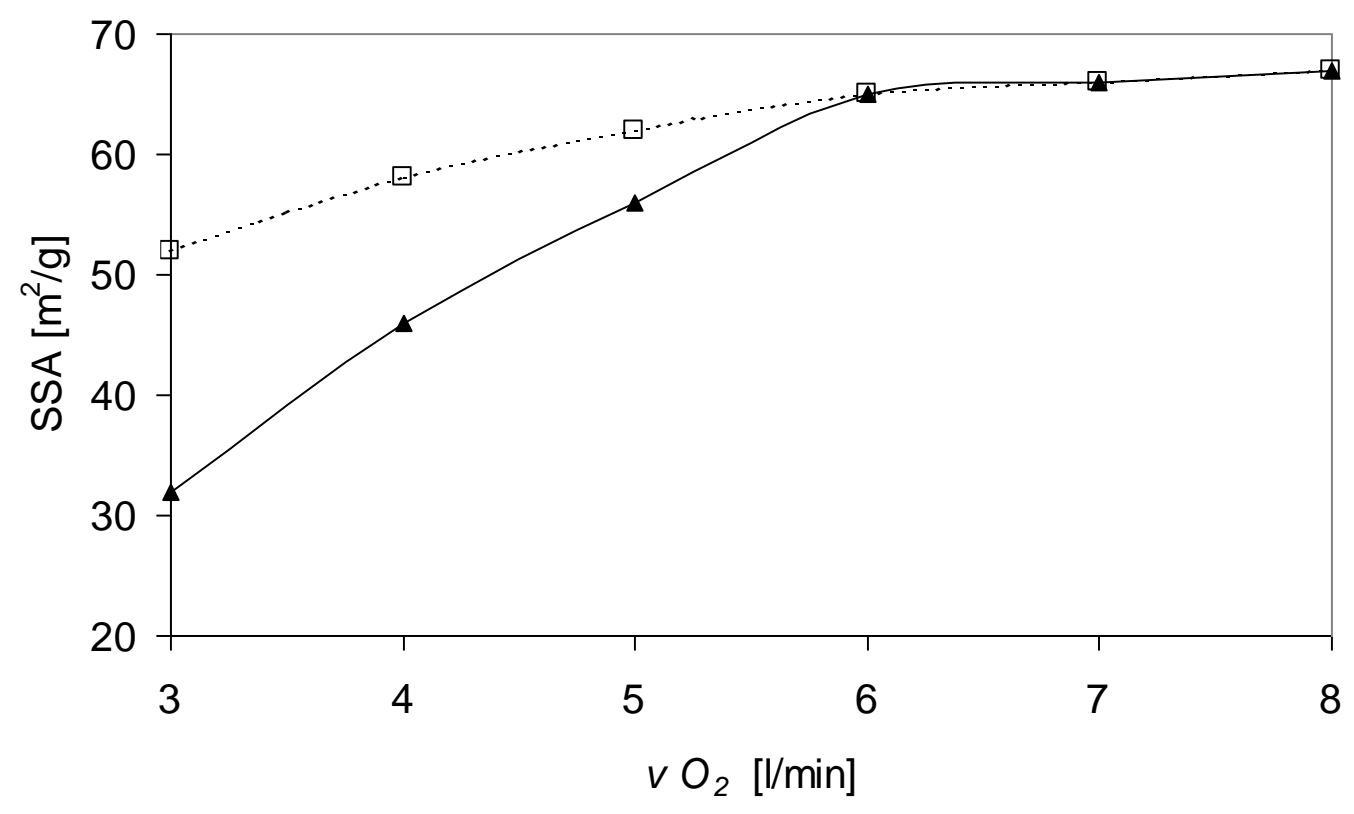


Fig. 11

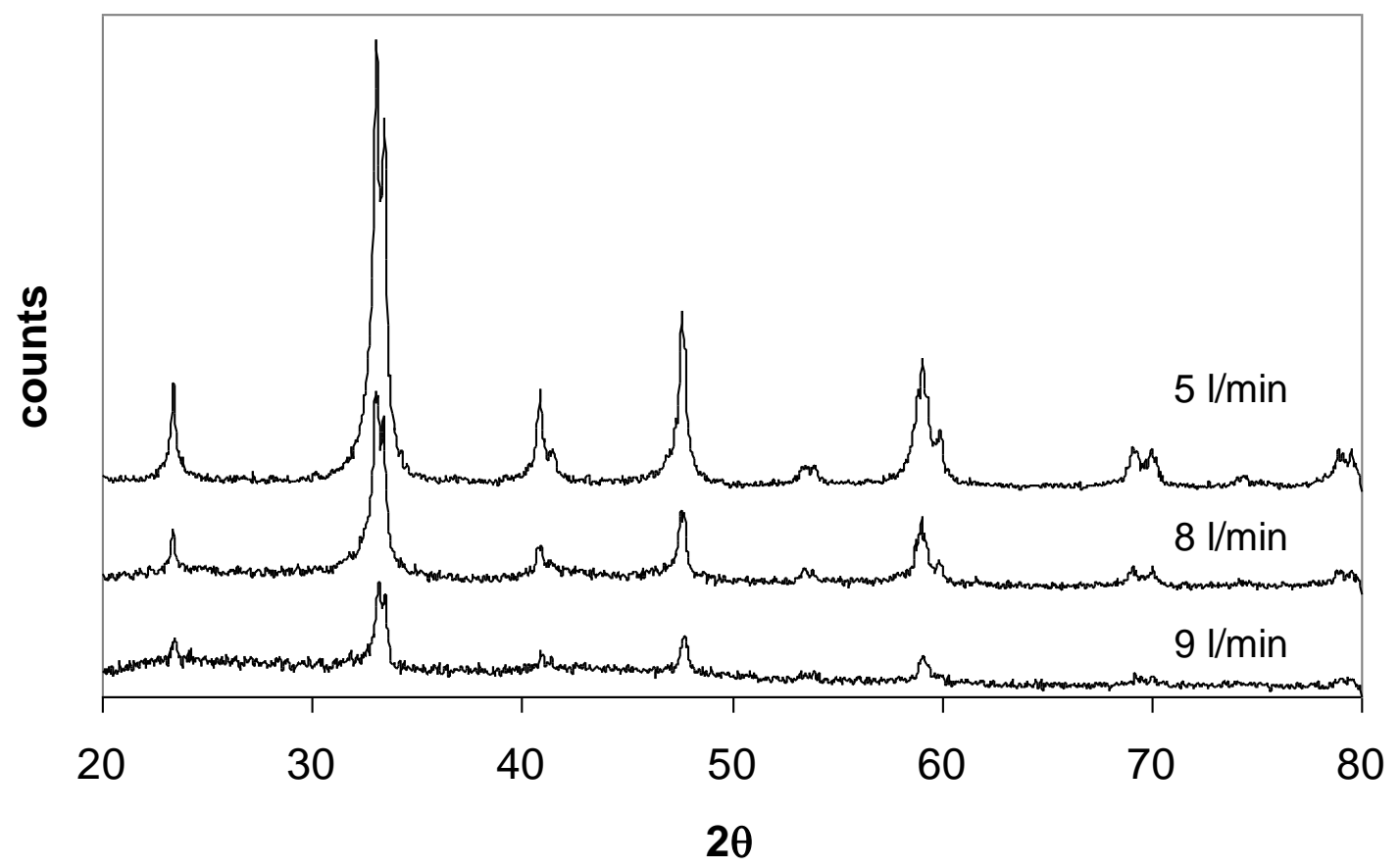

Fig.12

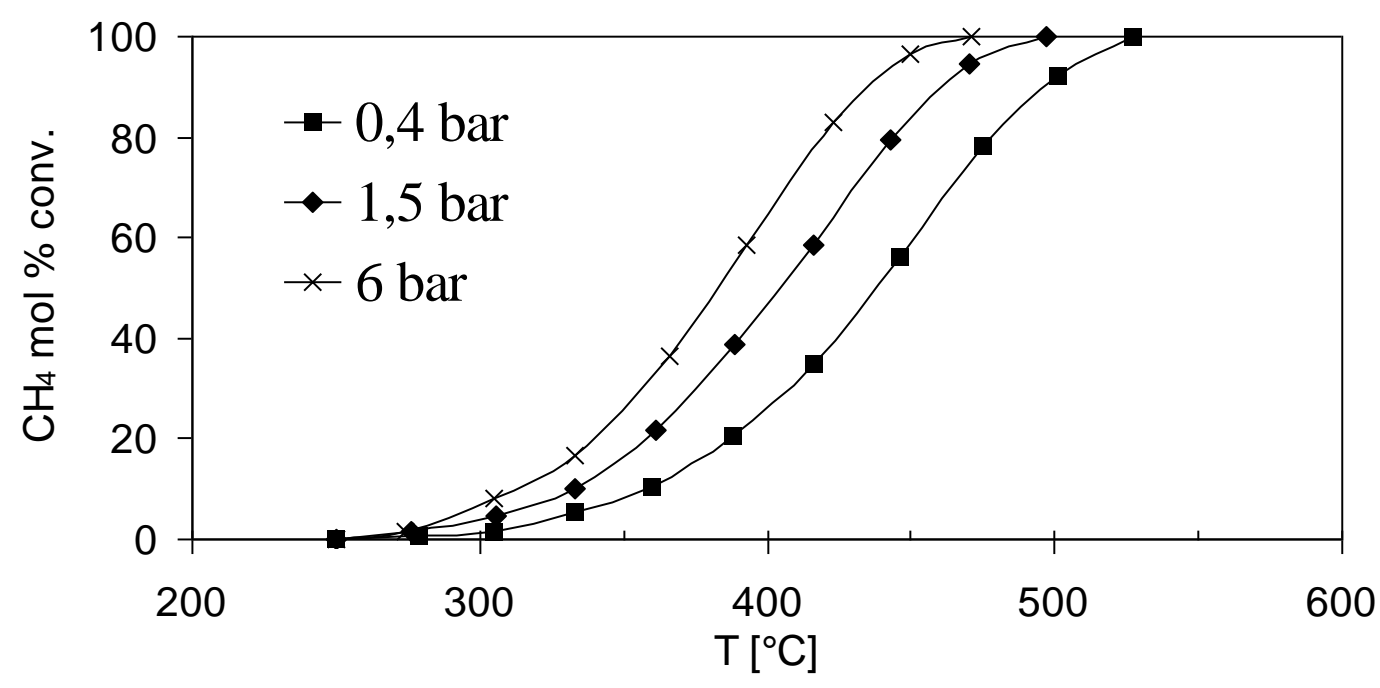


Fig.13

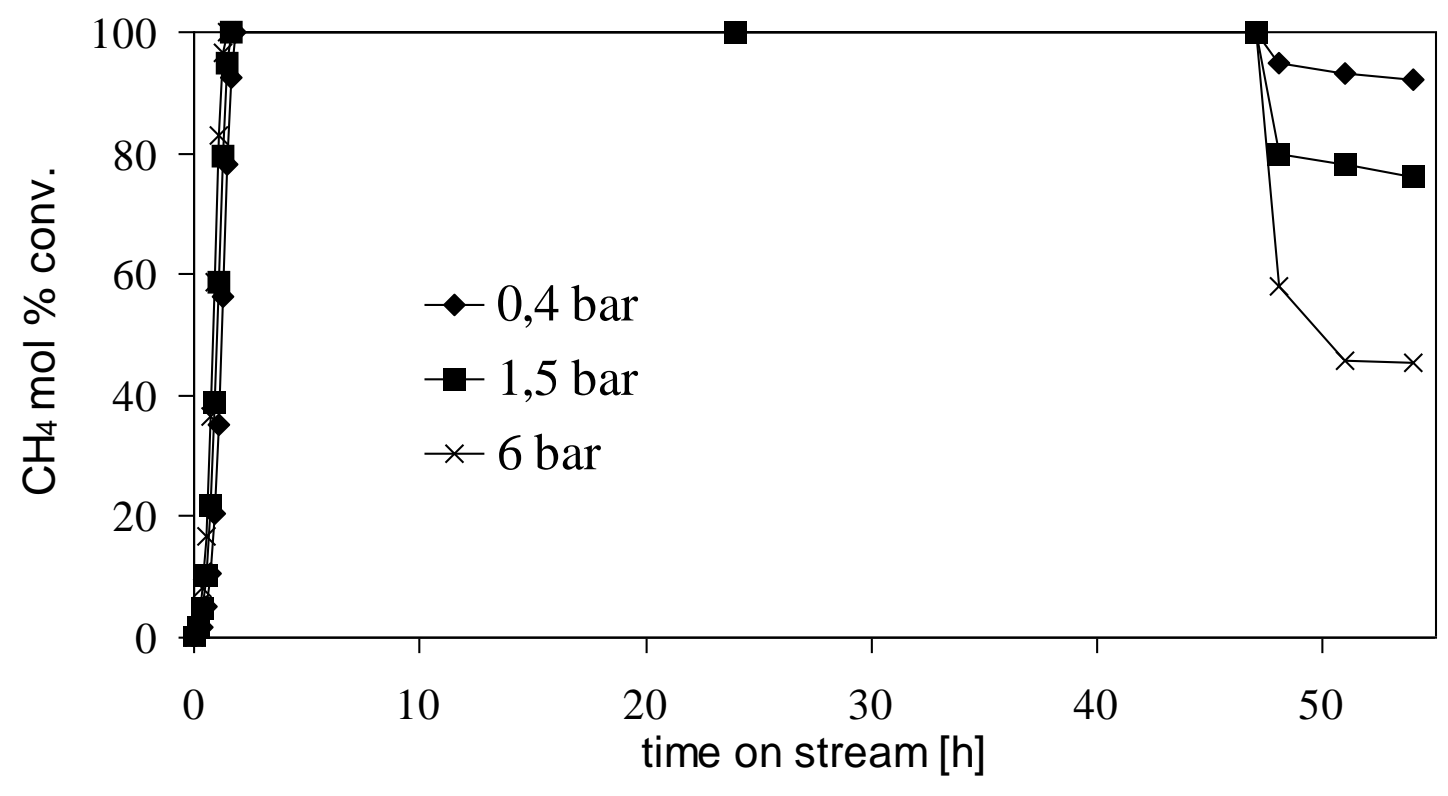

Fig.14

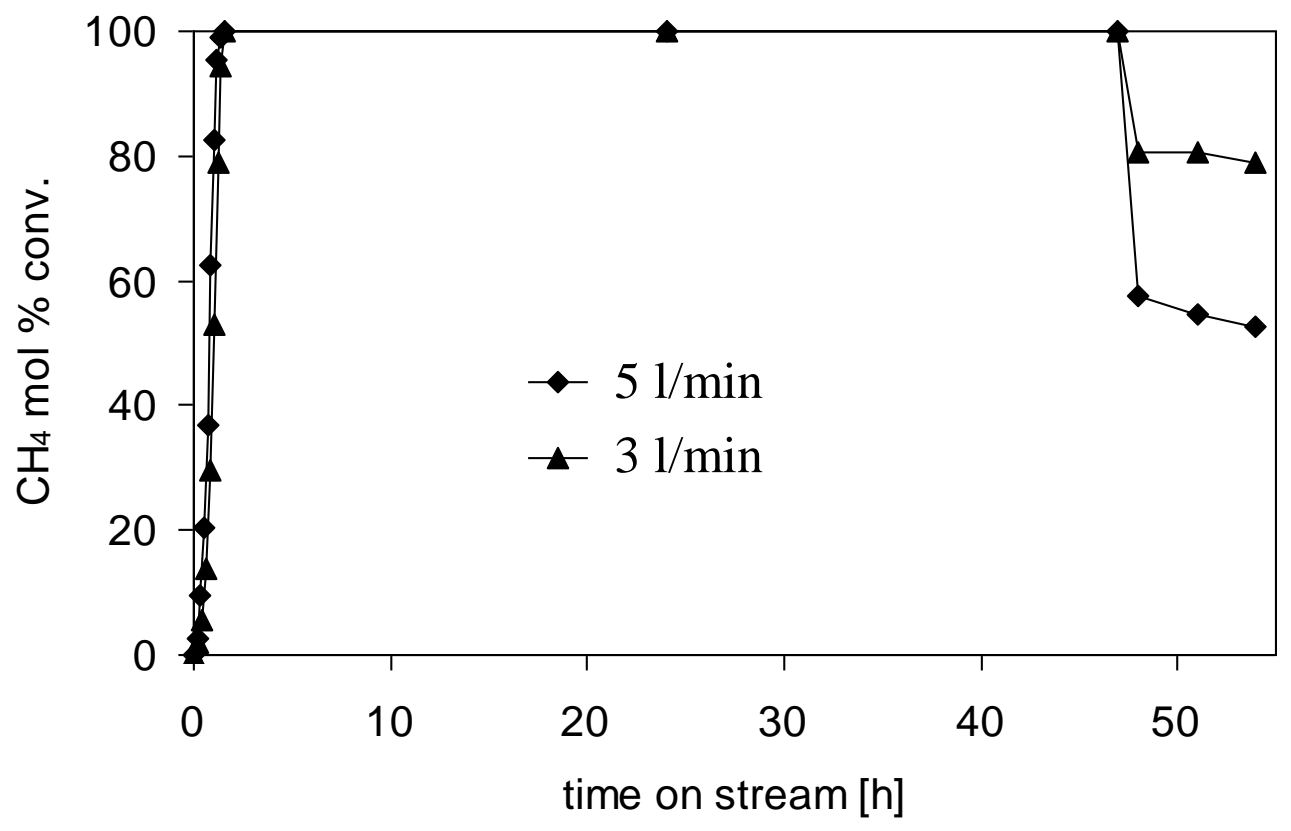

